\title{
О генезисе статального пассива и о различии пассивных форм НСВ и СВ в русском языке
}

\author{
АРПАД ОРОС \\ Orosz Árpád, Budapest, Orbánhegyi út 10, H-1126 \\ E-mail: kobak@axelero.hu
}

\begin{abstract}
This essay is devoted to the explanation of the genesis of dynamic and statal passives, and to the different formal marking of imperfective and perfective forms in the Russian passive. It is claimed that the differences originate from the fact that both the -sja and the $-n / t$ morphemes were originally middle markers, and as with numerous other languages, Russian also belonged to the active type as opposed to present-day Russian belonging to the nominative type.

Keywords: statal passive, aspect, telicity, transitivity, reflexive vs. passive, active typol-
\end{abstract} ogy, middle voice

1. В языкознании имеется несколько определений статальности. Это тесно связано с тем, что данный термин играет чрезвычайно важную роль как при описании одних эгзотических и древних языков и праязыков, так и в современных направлениях семантического исследования. К тому же, в ряде грамматик (и здесь автор имеет в виду, в первую очередь, описательные грамматики) даже не дается определение термина, авторы ограничиваются лишь перечислением единичных глаголов. Что касается современной семантики, под глаголами со статальным значением понимаются глаголы с гомогенной временной структурой, которыми нельзя ответить на вопросы «Что он делает? / Что происходит?» Нетрудно заметить, что излагаемый подход годен для объяснения невозможности образования прогрессивных форм английских глаголов. С другой стороны, в языках активного строя, например в языке чочо, распространенном в Южной-Америке, выделяется категория статического глагола, однако эта статичность связывается со степенью активности произведителя действия, и, соответственно, упомянутый класс глаголов сочетается с инактивными именами. Таким образом, оппозиция динамических, статических и аффективных глаголов сопровождается противопоставлением активных и инактивных имен (Климов 1972, 12). В случае обоих истолкований, статальность воспринимается как признак лексический. В русской лингвистической традиции статальное значение страдательного причастия прошедшего времени, трактуется как семантическая категория, и говорится либо о статальном значении определенной формы глагола (причастия), либо об омонимии формы страдательного залога и формы со статальным значением. В то же время, как это будет ясно ниже, статальность в случае пассива в русском и других языках ближе ко второму истолкованию. 
2. В русском языке наблюдается тесная связь залоговости и аспектуальности. Это проявляется прежде всего в зависимости способа образования пассива от вида глагола. Далее, указывается и на то, что акциональное и статальное значения пассива носят характер глагольной семантики СВ и НСВ и сочиняются с глаголами СВ и НСВ соответственно (Храковский 1991, 141-155; Орос 2000, 263).

2.1. Пассив СВ неотделим от значения состояния (Храковский 1991, 141-155). Исходя из семантических соображений, это объясняется, в основном, так, что достижение предела всегда дает новое положение, по-иному, новое состояние дел как свой результат. Поскольку в случае пассива акцент ставится на объекте действия, над которым действие совершается, в отличие от актива, где имеется исходно-субъектная ориентация, на передний план выдвигается новое состояние объекта (Givon $1985,179)$. Нет спора среди лингвистов и о том, что новая ситуация, сложившаяся вследствие достижения предела и, в случае абсолютного предела, исчерпания действия самим собой, имеет длительный характер по отношению к точечному характеру действия, обозначаемого глаголом СВ действительного залога. Однако трактуемая новая ситуация, закодированная в языке страдательным причастием НСB, является двоякой. Стоит сравнить пассив в следующих предложениях:

(1) Не ходи в магазин, он закрыт.

(2) Дамы и господа, случилась трагедия: наш президент убит!

В наиболее типичном истолковании примера (1), говорящий указывает на саму ситуацию, тогда как в примере (2) он указывает косвенно на событие, при помощи представления нового положения дел. Согласно данному различию, (1) анализируется как статальный пассив, в то время как (2) был отнесен нами к акциональному пассиву, поскольку он обладает прагматическим значением сообщения о наступлении новой ситуации (Орос 1999; 2000).

2.1.2. Необходимо отметить, что СВ в русском языке, как правило, не указывает на длительное, протянутое во времени действие. Поэтому неудивительно, что форма СВ страдательного залога, указывающая на период, следующий за пределом, ни в коем случае не может указывать на действие. Выражаясь терминами собственно грамматики, мы имеем дело с дополнительным распределением действия и состояния: действие кодируется указанием на предел, а состояние указанием на постпредельный этап. Когда состояние сохраняется до момента речи, говорится о перфекте (Пупынин 1984). В случае конкретно-процессного значения НСВ не имеет смысла говорить ни о достижении предела, ни о перфектном значении.

2.1.3. Как известно, русский язык не относится к языкам, имеющим сложную систему грамматических времен. Грамматические оппозиции, в частности, оппозиция времен, выражающаяся синтаксическими средствами в некотрых других языках, таким образом выражаются мор- 
фологическими средствами, и, поскольку морфологические маркеры служат, в первую очередь, для выражения видового или залогового противопоставления, они являются косвенными, и носят характер семантической оппозиции. В частности, суффикс $-\mu / m$ выражает страдательный залог (по крайней мере отсутствие действительного залога, как это увидим ниже) глаголов СВ, но при этом передает и перфектное значение. В этом отношении русский язык последовательно выявляет флективные признаки, так как постфикс -ся, восходящий к возвратному местоимению как самостоятельной лексической единице, тоже примыкает к слову, образуя формы пассива.

2.1.4. Кроме предельности, переходность тоже играет важную роль в функционировании залоговости, но данная категория, называемая лексико-грамматическим разрядом (Бондарко 1976), имеет значительность не только в русском и других славянских, а во всех языках. Она непосредственно связывается с залогом, будучи в центре функцонально-сеиантического поля залоговости (Бондарко 1972; 1976) ${ }^{1}$. Сверх того, предельность и переходность связаны между собой. Как М. Клайман пишет, наблюдается тенденция к ассоциации сниженной переходности с нереальными и неточечными временно-модальными категориями глагола (Klaiman 1991, 95). Далее она добавляет, что неточечность и непредельные способы действия родственны (там же, 95). Данные утверждения кажутся слишком обширными, поэтому стоит посмотреть, как они проявляются в конкретных случаях в русском языке.

2.2. Как это считается общеизвестным в специальной лингвистической литературе, посвященной теме залога, глаголы на -ся характеризуются непереходностью (напр., Бондарко 1972; 1976). Более подробная специфика постфикса -ся будет изложена ниже. Существуют некоторые видовые пары, где в форме НСВ налицо -ся, а в форме СВ его нет. Сюда относятся пары: садиться-сесть; пересажсиваться-пересесть; ложиться-лечь ${ }^{2}$. Наличие постфикса в форме НСВ и его отсутствие в форме СВ объясняется отмеченной выше повышенной предельностью перфективных глаголов. Переходность и предельность, оказывается, имеют нечто общее, будучи разными формами проявления одного отвлеченного понятия, играющего значительную роль в поле залого-

\footnotetext{
${ }^{1}$ Теория функционально-семантических полей, как известно, исходит из семантического значения, и рассматривает способы его выражения. Множество тех элементов, для которых в большей или меньшей мере характерно некоторое общее семантическое значение, называется полем этого семантического значения или семантической функции. Своеобразие полевой теории заключается в том, что поля охватывают разнородные взаимодействующие языковые средства; средства лексические и грамматические (морфологические, синтаксические, словообразовательные), которые объединяются семантико-функциональной общностью.

${ }^{2}$ Наряду с видовыми парами, можно привести и лексические антонимы, где наличие/отсутствие постфикса поражает, ввиду сходного лексического значения, например: просыпаться/проснуться-засыпать/заснуть. В то же время, излагаемое в настоящей статье объяснение применимо и в этом случае.
} 
вости. С другой стороны, можно поставить следующий вопрос: если -ся указывает на интранзитивность ${ }^{3}$ глагола, как это утверждается представителями функциональной грамматики, то какую роль имеет постфикс в таких исконно непереходных глаголах как становиться, ложиться, проснутся? Поскольку сам постфикс -ся является весьма распространенным, и также разнообразным, обладая высокой функциональной нагрузкой, мы имеем основания полагать, что упомянутому отвлеченному понятию соответствует формальный маркер, обладающий большим диапазоном значений. Как замечает И. Пете, констатирующий существование упомянутой асимметрии в видовых парах, глаголы на -ся выражают процесс (Пете 2000). Приняв данную характеристику, можно поднять вопрос, какую функцию постфикс -ся имеет в глаголах, выражающих действие и имеющих настолько динамический характер как заговориться, заиграться?

2.2.1. Уже Бэбби и Брэхт писали об общности возвратной и страдательной функций постфикса -cя, однако более исчерпывающий и обстоятельный анализ функций данной морфемы и родственных ей морфем в родственных индоевропейских, в частности, славянских и романских языках принадлежит С. Кеммер (Babby-Brecht 1975; Kemmer 1993; 1994). Сущность ее теории заключается в том, что в случае как рефлексива, так и пассива участники ситуации не обосабливаются в такой степени, как в случае обыкновенной переходной ситуации, иначе говоря, эти участники, или семантические актанты, менее различимы, границы между ними более размыты, нежели в случае типичного актива, находящегося в центре ФСП залоговости. Сниженная обособленность участников, ассоциирующаяся со сниженной предельностью и транзитивностью, показывается и в том, что форма -ся возникла из возвратного местоимения себя путем количественной редукции, и в русском языке она составляет одно фонологическое и орфографическое слово с глаголом (Орос 2001). Таким образом, в русском отмечается более интенсивное иконическое отражение содержания на форме, чем в других языках, о чем писал Хайман (Haiman 1983). В самом деле, в последнее время и в русской лингвистике высказывают такое мнение, что традиционное лексическое и лексикографическое различение и классификация глаголов на -ся как рефлексивов и пассивных форм является довольно зыбким, и следовательно, оно недержимо (Буланин 2001). Куда отнести, например, глаголы на -ся в следующих предложениях?

(3) Программа конференщии продолжается в актовом зале.

(4) Этот район именуется Обухово.

(5) Слухи в нашем коллективе быстро распространяются.

\footnotetext{
${ }^{3}$ Термины транзитивный - переходный; интранзитивный - непереходный; актив - действительньй залог; пассив - страдательныгй залог; возвратный глагол - рефлексив употребляются в статье синонимично, никакого понятийного различия между ними не проводится.
}

Studia Slavica Hung. 46, 2001 
Являются ли они возвратными глаголами или формами страдательного залога? Нельзя не согласиться с классиками русского языкознания, утверждавшими, что -ся «указывает на то, что действие замкнуто в сфере субъекта», однако это утверждение получает более глубокое содержание в свете интерлингвистических исследований, проведенных в рамках теоретической лингвистики. Сюда можно отнести и некоторые способы глагольного действия, упомянутые выше, например сативно-аугментативный: наговориться, наиграться; финитивный, со значением облегчения: отвоеваться, отмучиться; интенсивный, со значением удовлетворенности, увлеченности: заговориться, засматреться. Несомненно, здесь увеличивается значимость роли субъекта. (Относительно аналогичных явлений в других языках см. работу М. Арсе-Ареналеса (Arce-Arenales et al., 1994).

3. Выше говорилось о статальном значении страдательного причастия на $-\mu / m$ и об общем значении постфикса -cя. Их связывает пассивное значение в современном русском языке. В то же время, форма синтетического пассива употребляется лишь для выражения акционального значения страдательности. Можем дополнить вышеупомянутое замечание И. Пете о процессуальном значении форм на -ся тем, что -ся в глаголах садиться, ложиться подчеркивает динамичность ситуации по сравнению с ситуациями, обозначаемыми глаголами сидеть, лежать. ${ }^{4}$ Встает вопрос, почему формы страдательного залога НСВ и Св выражаются по-разному? Из вышесказанного следует, что обе формы, т.е. формы на $-\mu / m$ и $-c я$, первоначально не были связаны ни с точечными, ни с предельными событиями. Что касается современного этапа русского языка, аналитический пассив, когда он выражает статальность, что оказывается преимущественным, не может быть предельным, тогда как о синтетическом пассиве, передающемся при помощи -ся, было высказано хотя и несколько категоричное мнение, согласно которому он является всегда предельным, в отличие от форм НСВ действительного залога (Пупынин 1984) ${ }^{5}$. Если это так, то нечему удивляться, дополнительная дистрибуция морфологического обозначения пассива НСВ и СВ получает логическое объяснение.

3.1. Объяснить поведение некоторых конструкций на плоскости современного языка гораздо легче, если принять во внимание более

${ }^{4}$ На это можно возразить, что в формах становиться, ложиться наличие постфикса следует из стремления избежать транзитивную интерпретацию по аналогии транзитивных глаголов с суффиксом -и, например готовить, представить, рубить, уложить и т.д. и т.п. Однако данный подход не объясняет почему нет данного постфикса, например, в моторных глаголах ходить, лазить.

5 Представление Ю. А. Пупынина о предельности не вполне совпадает с мнением Храковского. Пупынин считает, что все глаголы СВ предельные, тогда как по Храковскому в случае семкльфактивных глаголов СВ не имеет смысла говорить о пределе. Однако, глаголы НСВ не относятся к этой группе глаголов. 
ранние стадии языка. Ранние стадии, в свою очередь, иногда напоминают структуру других языков, находящихся на более ранних этапах развития. Обнаруживаются следующие тенденции в одних азиатских и североамериканских языках:

3.1.1. Референт подлежащего предложения не может обладать меньшим потенциалом контролирования действия, чем референт какой-нибудь другой части предложения. В корейском, например, предложение, соответствующее русскому эквиваленту

(6) Мужчина гоняется за мячем

не имеет т.н. пассивного эквивалента. Ситуация является аналогичной в языке навахо, где эквивалент предложения

\section{(7) Девочка выпила воду}

тоже немыслима в форме страдательного залога. В то же время, предложения, выражающие значение типа 'Он беспокоен от нехватки времени' (буквально: 'Его гоняет время'.) в корейском, и 'Лошадь ударила мужчину ногой' в навахо не встречаются в активе, только в пассиве (Klaiman 1988; 1991). Поскольку в этих языках объект предложения, выступающий как подлежащее страдательного предложения, в отличие от субъекта (производителя действия), не располагает способностью контролировать ход событий, изложенная в сжатой форме тенденция в значительной степени затрудняет формирование пассива. Хотя в русском не имеется непосредственных доказательств аналогичной тенденции, обращает на себя внимание тот факт, что формы на -ся первоначально не представляли собой чисто страдательное значение. Формы на -н/m, обладавшие, первоначально, статальным значением (Jespersen 1963, 274), как и аналитические или перифрестические страдательные формы в остальных индоевропейских языках, были тоже дальше от центра ФСП залоговости. Обращает на себя внимание и конструкция типа

(8) Лодку унесло водой

(9) Генерала раздавило танком 6 ,

до сих пор не получившая убедительного объяснения в литературе, ведь в ней объект тоже в винительном падеже, и творительный падеж

6 Тем не менее, существуют различия между предлставлениями носителей двух языков, корейского и навахо. В последнем способность контролирования ситуации теснейшим образом связано с онтологическим статусом элемента, т.е. предмет или животное никогда не обладает большей способностью контролирования, нежели лицо. В это же время, в корейском способность контролирования приписывается и лицу и предмету, наделенному большей физической силой или другим свойством, облегчающим контролирование. Предложение (9) говорит о том, что в этом отношении русский ближе к системе корейского.

Studia Slavica Hung. 46, 2001 
тоже указывает на отсутствие сознательного контроля над описываемыми ситуациями ${ }^{7}$. При этом сравнительное рассмотрение языков выявляет, что винительный падеж еще дальше от возможности приписать способность контролирования ситуации референту данной части речи, нежели творительный.

3.1.2. Как было упомянуто в начале настоящей статьи, существуют языки активного строя среди языков иных континентов. Данное название ведет свое начало от наличествующих в языке активных и инактивных (стативных) глаголов. Они различаются просто наличием/ отсутствием динамики в глагольной семантике. Итак, не стоит путать активные языки и активные глаголы, с одной стороны и активную (действительную) конструкцию в языках номинативного строя, с другой. Транзитивные глаголы могут быть только активными, в то время как интранзитивные могут быть как активными, например эквиваленты глаголов 'играть', 'бегать', 'летать', так и инактивными, например эквиваленты глаголов 'оставаться', 'висеть', 'болеть', 'стоять', 'лежать'. Итак, трактуемая система отличается от эргативного строя, потому что там глаголы противопоставлены на основании транзитивности. Правда, большинство лингвистов считает активный строй видоизменением эргативного, но многие разделяют такое мнение, что активный строй кладется в основу и эргативного и номинаимвного строев, где, как известно, доминирующим противопоставлением является оппозиция субъекта (подлежащего) и объекта (прямого дополнения). Из сказанного вытекает, что наблюдается своего рода асимметрия транзитивных и интранзитивных глаголов в активном строе, и это усиливается и тем, что падеж подлежащего интранзитивных глаголов может быть двоякий, активный или инактивный, в зависимости от того, приписывается ли способность контролирования ситуации подлежащему, тогда как подлежащее активного глагола всегда в активном падеже. Для того, чтобы установить равновесие, языки активного строя начали различать транзитивные глаголы по наличию/отсутствию способности субъекта контролировать ситуацию ${ }^{8}$. По мнению Клайман, излагаемый процесс напоминает происхождение существовавшего в мертвых индоевропейских языках (санскритском, древнегреческом) медиального (среднего) залога, где оппозиция актива и медиума разделила переходные глаголы на два залоговых класса (Klaiman 1991, 65). Согласно общепринятому и часто цитируемому определению Дж. Лай-

\footnotetext{
7 Это потверждается и неграмматичностью данной конструкции, когда в форме творительного падежа лицо: Крышу сорвало ветром/*мальчиком, ведь лицо, в основном, может контролировать ситуацию.

${ }^{8}$ В случаях перехода языка из активного строя в эргативный строй наоборот, интранзитивные глаголы были расщеплены, поскольку активные непереходные глаголы начали маркироваться как инактивные.
} 
онза (1978, 396): «Медиум (когда он противопоставлен активу) означает, что «действие» или «состояние» затрагивает субъект глагола или его интересы». Хотя процитированная дефиниция представляется крайне общей, бытуют примеры, оправдывающие справедливость сравнивания двух процессов. Например, в санскрите на основании эквивалента

(10) Девадатто сгибает палку

возник эквивалент предложения

(11) Палка сгибается,

в котором медиальный залог указывает на спонтанность процесса, имеющего место без содействия постороннего действующего (агенса).

Бросается в глаза, что приведенный выше пример претендует на статус медиума и в русском. Действительно, уже в грамматике В. В. Виноградова (1972, 495), написанной вслед за предшествующими ему языковедами, аналогичные употредления -ся были отнесены к средневозвратному значению. В то же время, позиция Кеммер, относящей все формы на -ся и родственные им формы в других языках к медиальному залогу, кажется слишком категоричной (Kemmer 1993; 1994). Предложенный нами выше подход не противоречит данному анализу (подробнее см. ниже). Суммируя сказанное, хочется сказать, что постфикс в русском воспринимается как морфема, указывающая одновременно на непереходность глагола и на наличие процессуальности, или значительной степени динамики (активности). Это соответствует дополняющим друг друга вышеупомянутым характеристикам формы на -ся, данным А. В. Бондарко $(1972,1976)$ и И. Пете $(2000)$ соответственно.

3.2. Обратимся к причастиям на $-\mu / m$. Они тоже выражают непереходность, но не выражают однозначного наличия динамики. Естественным образом задается вопрос, может ли быть воспринята не очень тесная связь между двумя морфемами в пассиве как более тесной в функциях, отличающихся на первый взгляд от пассива? Ответ на этот вопрос является утвердительным. Рассмотрим следующие предложения:

(12)а. Маша часто огорчается. - (12)б. Маша огорчилась. - (12)в. Мама огорчена.

(13)а. Иван нелегко расстраивается. - (13)б. Иван очень расстроился. (13)в. Иван очень расстроен.

(14)а. Дверь открыввается. - (14)б. Дверь открылась. - (14)в. Дверь открыта.

(15)а. Яички мальчиков опускаются не сразу после рождения. - (15)б. У него яички опустились слишком рано. - (15)в. У трехлетнего мальчика яички уже опущеньь.

(16)а. Замки разваливаются если их не ремонтируют каждые двадиать лет. - (16)б. Замок графа Дракуль развалился после казни хозяина. - (16)в. Давай не ехать в Обломовск! Музей закрыт, замок развален. 
(17)а. Шельф вокруг Антарктидь нередко погружается. - (17)б. Шельф погрузился. - (17)в. Шельф погружен (пример Князева 1989).

Очевидно, что предложения а. и б. передают значение процесса, в которых достижение предела не нуждается в производителе действия, что связано с семантикой описываемых событий, получающихся спонтанно, и представляющих собой преимущественно явления психики, биологических организмов и естественной природы. Предложения в. передают состояние, возникшее по достижении предела как завершения данного процесса, или просто состояние без указания на какой-нибудь предшествовавший состоянию процесс. В специальной литературе этот подтип статального значения называется стативом и отличается от результатива, предполагающего наличие агенса (Храковский 1991, Князев 1989). Последним автором задается вопрос, почему нет стативного истолкования предложения (18) и почему (19) неграмматично (там же, 87).

(18) На веревке повешены платья.

(19) *На дереве повешены яблоки.

Однако неграмматичных примеров немало, см.

(20) *На улице поставлень деревья.

4. Князев разграничивает в своей работе результатив и статив, однако он не дает объяснения любопытному явлению в русском языке. Объяснение заключается в следующем: Все эти глаголы, позволяющие стативную, или непроизводную интерпретацию, имеют соответствующие так называемые возвратные глаголы с постфиксом -ся, в отличие от глаголов поставить, повесить ${ }^{9}$. Итак, можно заключить, что наблюдается взаимосвязь между наличием в русском языке своего рода «возвратного» глагола и формы со значением непроизводного состояния. Можно заключить, что формы глагольных троек в вышеприведенных примерах составляют одну парадигму и истолкование стативного, или непроизводного состояния у формы причастия на $-\mu / m$ имеется лишь в тех случаях, когда имеется и форма глагола на -ся. С другой стороны, нет формы на -cя, если, как в случае nocmaвumb, nовесить, действие немыслимо без действующего агенса (Babby-Brecht $1975)^{10}$. Поскольку в данных предложениях нет агенса, т.е. не имеет

${ }^{9}$ Возвратный глагол повеситься имеет специальное значение, в котором и речи нет о сниженной обособленности участников ситуации. Субъект и объект совпадают, но субъект производит действие сознательно и целенаправленно.

$10 \mathrm{~B}$ это же время, Бэбби и Брэхт и другие исследователи преувеличивают значительность агентивности. По мнению Бэбби и Брэхта, никакого (ни результативного, ни стативного) статального значения нет у причастий, образованных от глаголов, предполагающих действие агенса. Это не подтверждается нашими примерами: $O н$ не узнал особняк друга, потому что забор был выкрашен в синий ивет. См. и венгерский пример и его русский эквивалент: Jelezve van 'Кнопка «выход» нажата.' (На автобусах). Отсут- 
смысла говорить о производителе действия, и объект тоже не проявляет свойства типичного агенса, не стоит говорить ни о страдательном залоге относительно форм на $-\mu / m$, ни о возвратности относительно форм на -ся. Данные глагольные формы можно назвать формами медиального залога, как это сделано нами (Орос 2001). Вслед за другими исследователями, Гаврилова $(1998,1999)$ называет формы статального, т.е. и производного и непроизводного пассива вообще, включая и приведенные конструкции на $t / m$-, объектным квазипассивом. В то же время, она не занимается ни вопросом результативности/стативности, ни взаимосвязью форм на $-с я$ и $-\mu / m$. Она относит формы на $-\mu / m$ к «статальному виду», не обращая внимания на то, что различие между формами, например, воспаляется и воспален в основном не аспектуальное, так как они выражают допредельный и постпредельный этапы одного предельного процесса. Она осазнает, что эти формы являются членами одной парадигмы, но, по-видимому, не приписывает особого значения взаимосвязи наличия формы на -ся и формы на $-\mu / m$ со значением непроизводного состояния.

5. Изложенная в последнем абзаце аргументация соответствует и теории о первичности статального значения форм на $-\mu / m$ по отношению к акциональному значению, и выводам, сделанным представителями контенсивной типологии. В частности, подлежащее в конструкциях, названных нами медиальными, не мыслится как участник действующий, но также не мыслится как объект, подчиняющийся действию извне. Согласно гипотезе, нуждающейся в детальном изучении при помощи сопостовления разных других языков, как возвратные конструкции, предполагающие действующий субъект в форме именительного падежа, так и страдательные конструкции, предполагающие объект в форме номинатива, затрагиваемый действием субъекта, присутствующего или не присутствующего в предложении, восходят к медиуму в историческом плане. См. распространенное мнение, согласно которому первоначальное залоговое противопоставление в индоевропейских языках представляло собой оппозицию актива и медиума, на которую оппозицию позднее наслоилась оппозиция актива и пассива, напр. (Klaiman 1991). Когда закон, согласно которому подлежащее должно соответствовать производителю действия (или субъекту состояния) перестало действовать, предложение начало описывать такое событие, в ходе которого с кем-то что-то происходит. Иначе, событийность и затрагиваемость подлежащего действием постороннего участника могло быть выражено одновременно. О двунаправленном развитии медиума в рефлексив и пассив, и о том, что данный переход

ствие статального значения у причастия объясняется, на наш взгляд, тонкими семантическими правилами, нуждающихся в дальнейшем исследовании.

Studia Slavica Hung. 46, 2001 
произошел постепенно, свидетельствует и то обстоятельство, что пассив вытесняется только наиболее типичным проявлением возвратности, собственно-возвратными формами. Ср. (21) и (22), (23) и (24), (25) и (26):

(21) Наши ученики переписываются с пионерами Советского Союза (взаимно-возвратное значение) - (22) Тексты, содержащие причастия, переписываются учениками десятого класса (пассивное значение)

(23) Смотри, поезд останавливается (средне-возвратное значение) (пример Виноградова) - (24) Поезд останавливается стрелочником (пассивное значение)

(25) Не входи, Ира одевается (собственно-возвратное значение) - (26) * Она еще маленькая, она одевается бабушкой (пассивное значение) ${ }^{11},{ }^{12}$.

6. Подводя итоги сказанному, мы хотим подчеркнуть следующее: в статье было показано, что различия акционального и статального пассива восходят к разным этапам развития языка, что, должно быть отражением различия в мышлении людей разных эпох и разных культурных сред. Разное грамматическое оформление страдательных форм глаголов НСВ и СВ следует из первоначальных, не специально залоговых значений маркеров, тесно связанных с аспектуальными свойствами видов.

\section{Литература}

Бондарко А. В. 1972 - К теории поля в грамматике - залог и залоговость: Вопросы языкознания [= ВЯ] 1972/3. 20-35.

Бондарко А. В. 1976 - Теория морфологических категорий. Ленинград 1976.

Буланин Л. Л. 2001 - О некоторых сложных проблемах категории залога: Исследования по языкознанию. К 70-летию члена-корресрлндента РАН А. В. Бондарко. СПб. 2001, 163-169.

Виноградов В. В. 1972 - Русский язык (Грамматическое учение о слове). Москва 21972.

Гаврилова В. И. 1998 - Краткое причастие на $-4 / m$ как форма статального вида страдательного залога: Типология вида, Проблемы, поиски, решения. Отв. ред. М. Ю. Черткова. Москва 1998, 99-114.

Гаврилова В. И. 1999 - Сознательные действия, стихийные процессы и ситуация создания и снятия преграды: Логический анализ языка. Языки динамического мира. Дубна 1999, 159-174.

11 Примеры (23) и (25), в самом деле, могут быть отнесены к медиальному залогу, иначе говоря, переход из медиума в рефлексив является скорее интерпретационным, ввиду тройки: Она одевается-Она оделась-Она одета, вполне устраивающей структурным, хотя не семантическим, критериям медиума. Пассивное истолкование вытесняется и в случае аналитической формы: *Она одета прабабушкой

12 В некоторых случаях наблюдается полная функциональная синонимия форм на -ся и -н/m с медиальным значением, например: Упомянутое явление связывается с перенаселенностью - Упомянутое явление связано с перенаселенностью Данное обстоятельство лишний раз подчеркивает главные тезисы статьи, а именно, что пассивное истолкование форм первоначально медиального значения связано с повышенной степенью предельности и повышенной обособленностью участников ситуации. 
Климов Г. А. 1972 - К характеристике языков активного строя: ВЯ 1972/4, 1-13.

Климов Г. А. 1977 - Типология языков активного строя. Москва 1977.

Князев Ю. П. 1989 - Конструкции с русскими причастиями на $-н / m$ в семантической классификации предикатов: ВЯ 1989/6. 83-94.

Лайонз Джон 1978 - Введение в теоретическую лингвистику. Москва 1978.

Oрос A. 1996 - Семантические значения пассива и их взаимосвязи с аспектуальностью: Теория и практика преподавания славянских языков. Ре́cs 1996, 119-125.

Oрос A. 1999 - Семантические значения пассива и их взаимосвязи с аспектуальностью и темпоральностью в русском, венгерском и английском языках: Studia Russica 17 (Budapest: ELTE, 1999) 207-213.

Opoc A. 2000 - К вопросу об аспектуальности страдательных конструкций: NyelvAspektus-Irodalom, Köszöntő könyv Krékits József 70. születésnapjára (Szerk.: Györke Zoltán). Szeged 2000, 263-267.

Oрос A. 2001 - К вопросу о медиальном залоге в русском языке: Вестник. «Современный Русский язык: функционирование и проблемы преподавания» ФИРЯП, Российский Культурный Центр, 2001.

Пете И. 2000 - Vorgangspassiv и Zustandspassiv в русском языке: Köszöntő könyv Papp Ferenc 70. születésnapjára. Debrecen 2000.

Пупьнин Ю. А. 1984 - Взаимосвязи категорий вида и залога в русском языке при функционировании форм НСВ в пассивных конструкциях: Теория грамматического значения и аспектологического исследования. (Под ред. А. В. Бондарко.) Ленинград 1984, 175-189.

Храковский В. С. 1991 - Пассивные конструкции: Теория функциональной грамматики. Персональность. Залоговость. (Отв. ред. А. В. Бондарко.) СПб. 1991, 114-197.

Arce-Arenales M. et al. 1994 - Active Voice and Middle Diathesis/Voice, Form and Function. Amsterdam 1994, 1-16.

Babby L. H.-Brecht R. D. 1975 - The syntax of voice in Russian: Language 51/2 (1975) 342-367.

Givon T. 1981 - Typology and functional domains: Studies in Language 5 (1981) 163-199.

Haiman J. 1983 - Iconic and economic motivation. Language 59 (1983) 781-819.

Jespersen O. 1963 - The philosophy of grammar. London 1963.

Kemmer S. 1993 - The middle voice. Amsterdam 1993.

Kemmer S. 1994 - Middle Voice, Transitivity, and the Elaboration of Events: Voice, Form and Function. Amsterdam 1994, 179-230.

Klaiman M. H. 1988 - Affectedness and control, a typology of voice systems: Passive and Voice ed. by M. Shibatani, Amsterdam/Philadelphia 1988, 25-83.

Klaiman M. H. 1991 — Grammatical Voice. Cambridge University Press, 1991. 